\title{
Risk of multiple cross-over of control characteristics in multi-terminal HVDC
}

\author{
Carl Barker ${ }^{1}$, Robert Whitehouse ${ }^{1}$, Jun Lang ${ }^{2}$, Sheng Wang ${ }^{2}$ \\ ${ }^{1}$ Research and Technology, Alstom Grid Power Electronics Activity, Stafford, UK \\ ${ }^{2}$ School of Engineering, Cardiff University, Cardiff, UK \\ $凶$ E-mail: robert.whitehouse@alstom.com
}

\begin{abstract}
HVDC grids have been made practical with the introduction of the voltage source converter (VSC). The development of VSC technology has been, and continues to be rapid, with new converter topologies and new manufacturers entering the market. For the power transmission industry to fully exploit the benefits a 'multi-vendor' supply chain is considered essential. However, unlike AC grids, there is at present no standardised grid code for HVDC grids and interoperability of equipment and systems, purchased from many different and competing suppliers, is a major concern. Compatibility of control between converters supplied by different manufacturers has been considered by several groups such as CENELEC TC8X - WG6. The initial findings were that there was little reason to suggest that restrictions should be placed on which control strategy should be employed. However recent work uncovered an adverse interaction between converters with differing operating modes. This study illustrates how multiple operating points in the control characteristics could occur and show why such operation is undesirable and how it can be avoided by careful scheme design.
\end{abstract}

\section{Introduction}

With the introduction of the voltage source converter (VSC) into the field of HVDC power transmission the full advantages of multi-terminal HVDC systems or grids may, at last, be realised. However, it has often been stated [1-3] that for large power transmission grids to become a reality the supply of the equipment to that grid should ideally be multi-vendor. That is, the grid will be built by several, competing, companies and possibly over an extended period of time. In this way the development of DC grids will mirror that of $\mathrm{AC}$ grids. The presumption, therefore, is that an all-encompassing grid code will be developed which all suppliers adhere to. However, at the present time each manufacturer has created their own control concept and it is therefore possible, indeed likely, that DC grids will develop with converters employing differing control characteristics. In some circumstances the control method might be dictated by the application. For example a converter evacuating power from a wind farm must inherently employ a form of power control in order to maintain the wind farm AC system frequency.

In work undertaken by CENELEC (TC8X - WG6) technical guidelines for radial HVDC networks [4] an attempt was made to assess the interoperability of converters using different control strategies in the same HVDC grid. The studies were conducted using a simple four terminal radial VSC HVDC grid. The initial conclusions were that the various schemes would be compatible and there was little reason to suggest that restrictions should be placed on which control strategy should be employed.

Cardiff University, in collaboration with Alstom Grid, undertook a study on HVDC grid control. The studies involved both digital simulation (PSCAD/EMTDC) and physical modelling using the University's four-terminal VSC simulator. One aspect of the studies uncovered a potential adverse interaction between converters with differing operating modes. This interaction was due to multiple cross-overs between the different VSC converter control systems using different control characteristics.

\section{Basic control strategies}

Various control strategies for VSC converters connected to a HVDC grid have been proposed by manufacturers and academia [5-13]. The methods appear to be very different but broadly fall into three basic categories. These are master station control of DC voltage, shared responsibility of control of DC voltage and a hybrid of the two. Considerations for selecting a control strategy could include the power rating of the $\mathrm{AC}$ system in relation to that of the converter or the relative short circuit level at the point of connection. However, a major factor is the nature of the generation and or load to which the converters are connected. Two critical types are Wind Parks and Island Loads. Wind Parks, such as those being developed off-shore, consist of arrays of wind turbines connected to an off-shore AC grid with practically no local load. For these schemes the HVDC grid constitutes the only way of evacuating the generated power out of the system and as such the power flow through the converter must match exactly that generated by the wind turbines in order to maintain the off-shore grid frequency within an acceptable range. The feeding of isolated or 'island' loads where the HVDC grid supplies all, or at least a substantial part of the power to the island load, is a 'mirror' of wind farms. In this case the HVDC grid power in-feed into the island must match the load requirements in order to maintain the island $\mathrm{AC}$ system frequency within acceptable parameters. In either case there may be other local loads and or generators which, whilst perhaps not being as large a power rating as the HVDC grid connection, nonetheless have to be integrated into the overall power flow control strategy. Whatever the scenario, or generator/load mix, the overall control requirement is one of AC system frequency control operating on a converter power control loop.

In a HVDC grid, with converters potentially connected to combinations of isolated wind parks, island $\mathrm{AC}$ systems and 'conventional' AC systems, there will be converters with different control characteristics. These can be divided into two categories; those that have to maintain a power determined by their connected $\mathrm{AC}$ system and those that have to supply/sink power dictated by the DC grid requirements. The latter, commonly referred to as 


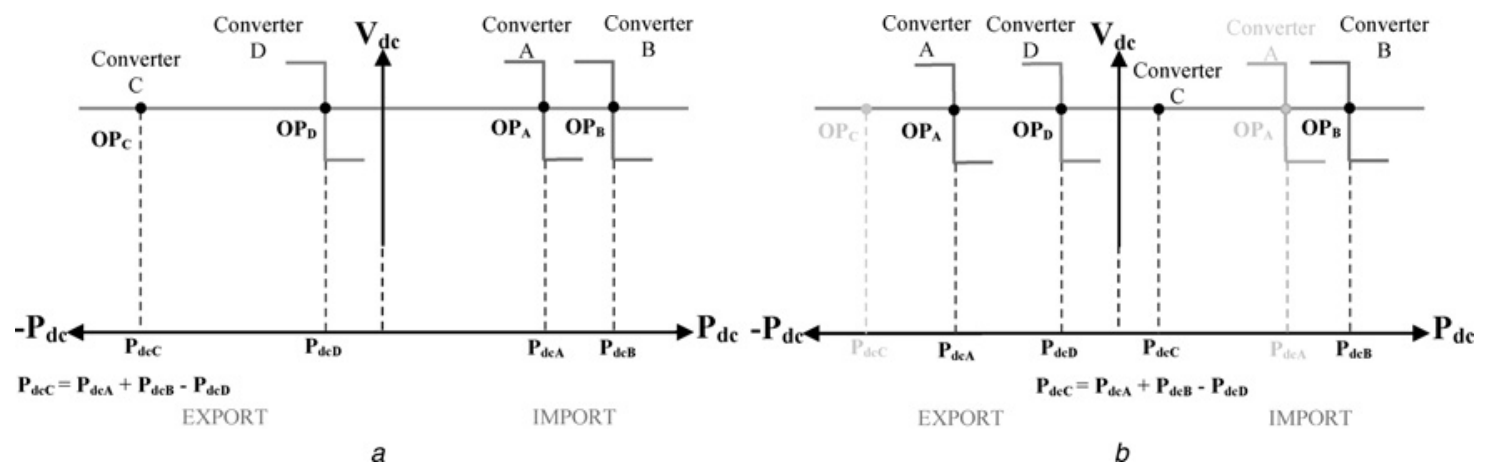

Fig. 1 'Slack' bus based control system for a four terminal HVDC grid

$a$ Simplified 'slack bus' DC power control

$b$ Change in power flow on a 'slack bus'

'slack' buses, would be expected to be connected to 'larger' more 'robust' ac systems where stochastic changes in power flow demand can be more easily accepted.

Examples of different control methods are described below. (The convention used here is; power flow from the AC system to the DC grid the converter is IMPORTING (rectifying) and DC current flowing from the converter into the DC grid is defined as positive DC current; conversely power flow from the DC grid to the AC system the converter is EXPORTING (inverting) and DC current flowing from the DC grid into the converter is defined as negative DC current)

\subsection{Slack bus}

An example of the static characteristics of a 'slack' bus based control system for a four terminal HVDC grid is shown in Fig. 1a. Here a single converter $\mathrm{C}$ (assumed to be an exporting station) is controlling the DC voltage whilst the other converters (A importing, B - importing, D - exporting) are operated in constant (direct) power control although in the case of converters A and B they could ultimately be controlling their respective $\mathrm{AC}$ system frequencies. Whereas the converters $\mathrm{A}, \mathrm{B}$ and $\mathrm{D}$ can change their power orders as required the power flow through converter $\mathrm{C}$ is determined by the difference between the other converters in the system. In other words the AC system attached to converter $\mathrm{C}$ has to accept the difference in power flowing from/to the grid. For example, changing the power supplied by converter $\mathrm{A}$ its effect on converter $\mathrm{C}$ becomes obvious (Fig. 1b). In this particular example converter A changed from an importing (rectifier) station to an exporting (inverter) station and in doing so forced converter $\mathrm{C}$, the DC voltage controlling station to change from an exporting to an importing station. Whereas this type of control allows for independent operation of converters A, B and D it makes the assumption that converter $\mathrm{C}$, and more specifically its associated $\mathrm{AC}$ system, can tolerate the new power flow conditions.

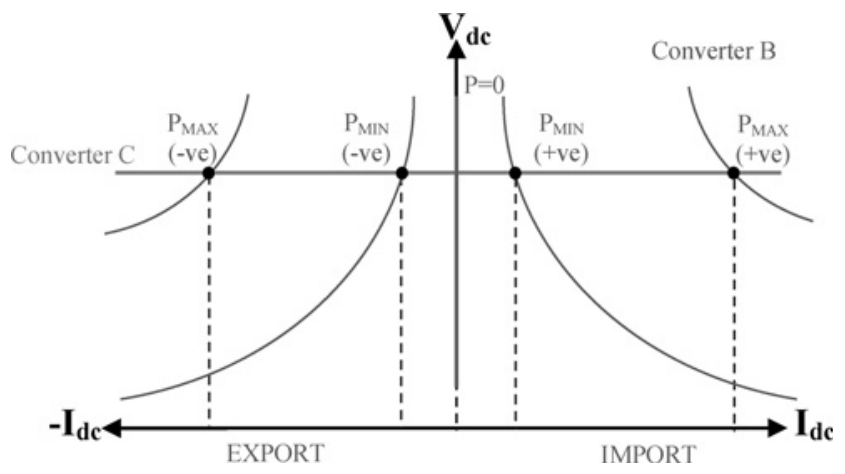

Fig. 2 Power control characteristic on a Vdc/Idc graph

However Fig. 1 does not give a direct representation of how the different types of characteristics interact. By redrawing with $V_{\mathrm{dc}}$ and $I_{\mathrm{dc}}$ as the axis (and omitting two converters for clarity) produces Fig. 2. It can be seen that the gradient of the constant power characteristic $\left(V_{\mathrm{dc}} / I_{\mathrm{dc}}\right)$ changes magnitude and sign with power order. If $V_{\mathrm{dc}}$ is fixed the gradient of the constant power characteristic is greatest at zero power and lowest at high power.

\subsection{Droop control}

An alternative to a 'slack bus' constant power system is to use a droop control [14]. In this system all converters that are not in power control are given a simple $V / I$ characteristic as shown in Fig. 3a. The advantage here is that all available converters, in accordance with their power orders and slope settings, share the responsibility of power changes within the DC grid. This is illustrated in Fig. $4 a$ where four stations are represented (drawn to show import and export with the separate current axis). In Fig. $4 b$
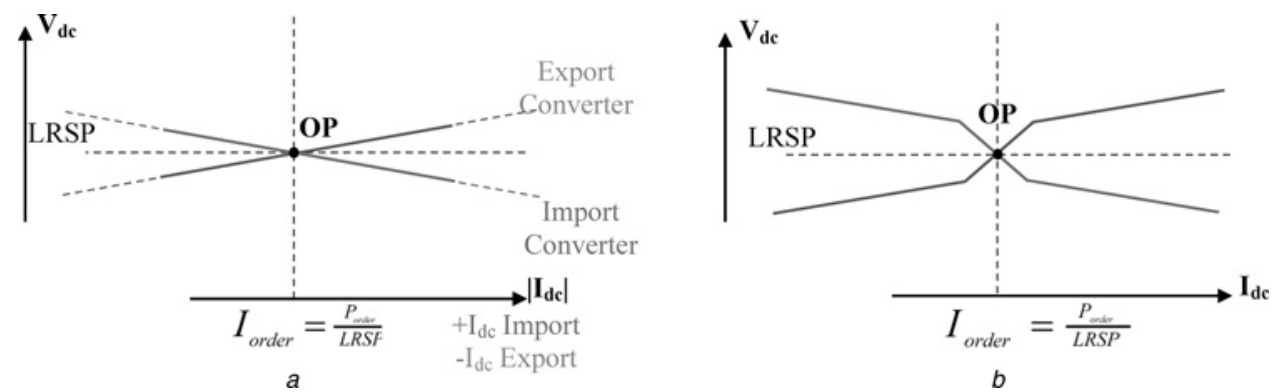

Fig. 3 All converters that are not in power control are given a simple V/I characteristic

$a$ Basic $V_{\mathrm{dc}} / I_{\mathrm{dc}}$ droop control

$b$ Alternative droop control 

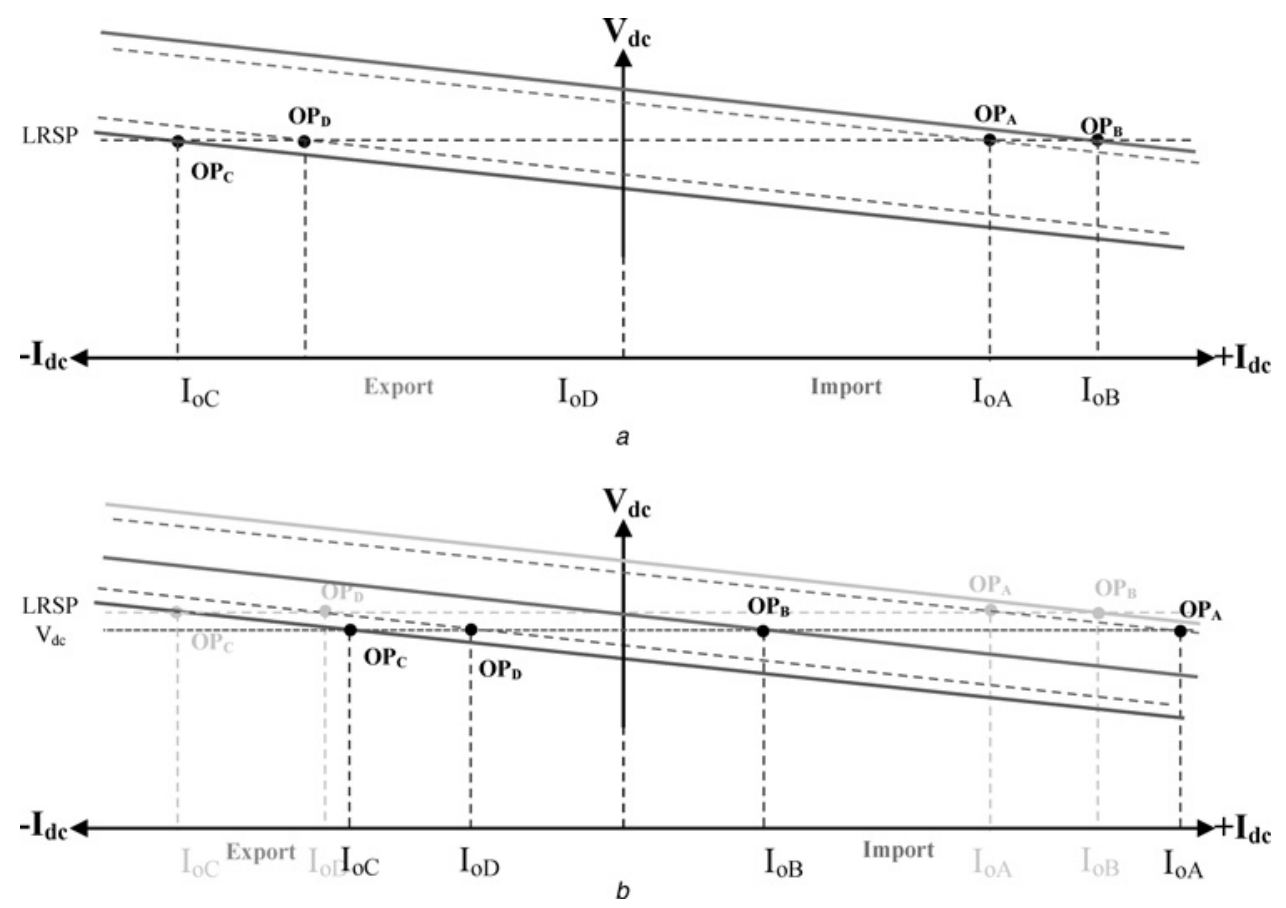

Fig. 4 Four stations are represented (drawn to show import and export with the separate current axis)

$a$ Four terminal HVDC Grid - droop control

$b$ Four terminal HVDC Grid droop control - converter B power order change

the power order to converter B has been arbitrarily changed (moving its droop characteristic downwards) and reduced the converter power delivered to the grid. The result is that the operating DC voltage moves away from the intended level (the load reference set point LRSP) and with it the operating points of all the converters also change. In time, errors in power flow are corrected by the grid controller re-dispatching the converters power orders and/or LRSP and/or slope settings.

\subsection{Alternative droop control}

A perceived disadvantage of droop control characteristics is that small variations in operating conditions or errors in local measurements can give changes in the operating power levels at each converter. For small changes in the operation of the grid this can be avoided by modifying the control characteristic to have a 'narrow' range, higher droop setting, at the desired operating point (Fig. $3 b$ ) [15, 16]. This ensures that small changes in the grid voltages will not result in significant power flow changes at the converter. Larger changes in DC voltage will take the converter outside this range and return it to a normal droop characteristic whereby it can again contribute to the 'slack bus' for the whole system.

\section{Interaction of control types}

To study the possible interaction between the various control modes a simple four terminal HVDC grid connecting two offshore Wind Park stations (WF1 and WF2) and two shore based stations (GS1 and GS2) was considered.

For the majority of cases involving converters in power control and droop control no adverse interaction was observed. However possible adverse interaction was found between exporting station (s) in power control with an importing station(s) in droop control with the alternative characteristic. Under this operating mode a condition could exist where the relative slope of the two characteristics could give rise to more than one possible operating point. Furthermore, it was seen that transitions between the operating points would occur for relatively minor changes in operation of the grid. These transitions manifested themselves as incorrect operating points for the scheme and potentially undesirable and unpredictable changes in the DC currents and voltages within the DC grid. This is illustrated in Fig. $5 a$. This condition can only exist if the gradient of the high droop section of the characteristic is greater than that of the constant power characteristic. It should be emphasised that these characteristics are not necessarily those of individual converters but the combined effect of all of the converters in the DC grid.

Initially the concern was that operation of the scheme would oscillate between the three possible operating points $\left(\mathrm{OP}_{1}, \mathrm{OP}_{2}\right.$ and $\mathrm{OP}_{3}$ ) however analysis shows, and later confirmed by simulation, that the operating point $\mathrm{OP}_{2}$ is not stable but $\mathrm{OP}_{1}$ and $\mathrm{OP}_{3}$ are. In the region between $\mathrm{OP}_{1}$ and $\mathrm{OP}_{2}$ where the difference between the operating point and the constant power characteristic is positive, that is, DC power is greater than that required. Any slight deviation into the region $\mathrm{OP}_{1}$ to $\mathrm{OP}_{2}$ would yield a greater positive error in power flow which would give rise to a further movement of the operating point away from $\mathrm{OP}_{2}$ to $\mathrm{OP}_{1}$; this is a positive feedback control region. Similarly, if the operation deviates slightly into the region from $\mathrm{OP}_{2}$ to $\mathrm{OP}_{3}$ the net $\mathrm{DC}$ power flow error is negative and the constant power controller will correct for this by increasing the converter power demand pushing the operating point further towards $\mathrm{OP}_{3}$. Again this is a positive feedback region of control. It is therefore certain that operation would not be at the desired operating point $\left(\mathrm{OP}_{2}\right)$. Whereas operation at $\mathrm{OP}_{1}$ and $\mathrm{OP}_{3}$ may be stable it cannot be guaranteed that small disturbances within the DC grid will not cause a change from one to the other. Any ambiguity in the operating point, and thus the DC voltage, affects all converters within the DC grid and will lead to all converters in droop control failing to transfer the demanded power to/from their respective AC systems.

A further complication can arise during power ramps where by any delays in the control systems (i.e. the power controller) will result in a transient error between the power orders to the power control and droop control converter(s). This is illustrated in Figs. $5 b$ and $c$. For example a rising power order may cause the operating point to be at $\mathrm{OP}_{1}$ (Fig. $5 b$ ); once the power ramp is complete the operating point would move to $\mathrm{OP}_{2}$, which is unstable. Operation would then move to either $\mathrm{OP}_{1}$ or $\mathrm{OP}_{3}$ 

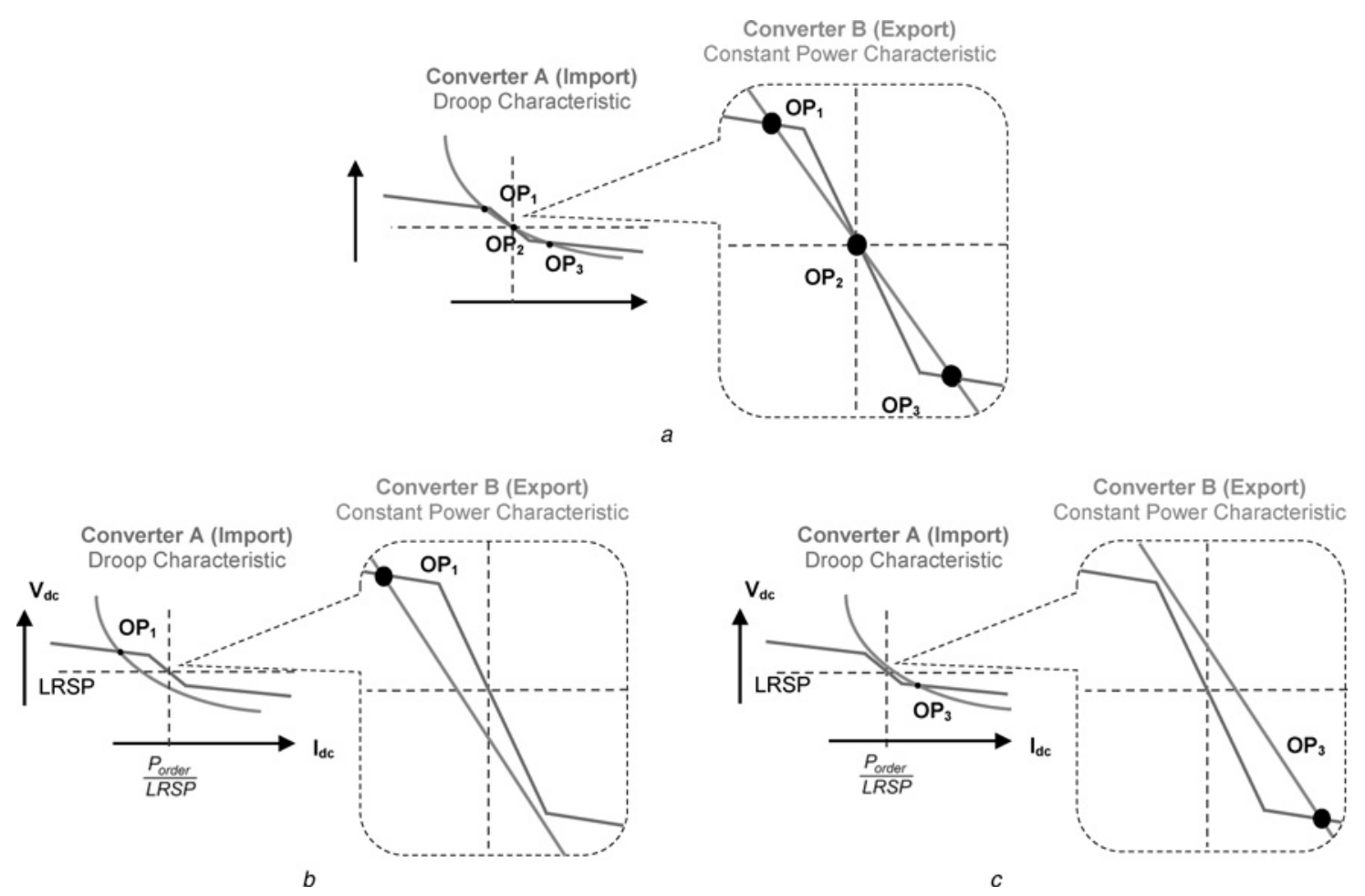

Fig. 5 Power controllers

$a$ Multiple operating points

$b$ Reduced grid power

$c$ Increased grid power

A similar situation can exist for power reductions where operation will be at $\mathrm{OP}_{3}$ during the power ramp as, again, the power controlling converter(s) will lag behind that of the droop controlled converter(s).

To avoid any ambiguity of the operating point, the value of high droop should be smaller than the slope of the constant power curve. Fig. 6 gives an example of a droop characteristic with a small 'undead' band (red) cross-over and a power curve (green). Within the band, if the droop $(|k|)$ is larger than the slope of power curve $\left|\left(\partial V_{\text {power }} / \partial I_{\text {power }}\right)\right|($ Fig. $6 a)$, there can be three different operation points while if the $|k|$ is smaller than the $\left|\left(\partial V_{\text {power }} / \partial I_{\text {power }}\right)\right|$ (Fig. 6b), there can only be one operation point.

Essentially, within a small (current) region, the power curve is almost linear, while the droop control characteristic is non-linear due to the difference between the slope inside and outside the active range. This non-linearity gives the potential a risk of multiple curve crossing. When the value of droop inside the band is larger than the slope of power curve, but conversely smaller outside the band, these two curves can have one crossing within the band, and two crossing outside the band.

To avoid the multiple operating points the maximum allowable value for the high droop setting can be estimated by the following analysis.

Within a DC grid composed of $n$ converters in droop control and $m$ converters in power control (Fig. 7), the sum of current flowing

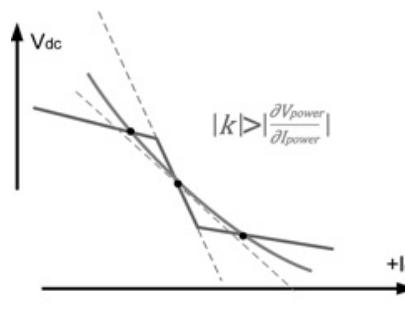

a

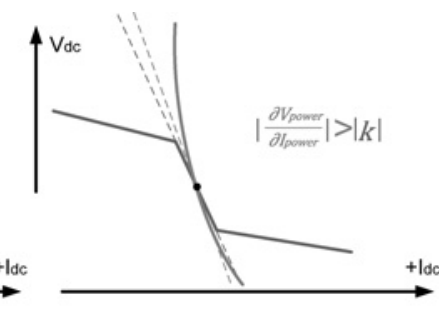

Fig. 6 Control interactions

$a$ Multiple operating points when $|k|>\left|\mathrm{d} V_{\text {power }} / \mathrm{d} I_{\text {power }}\right|$

$b$ Single operating point when $|k|<\left|\mathrm{d} V_{\text {power }} / \mathrm{d} I_{\text {power }}\right|$ through converters is balanced

$$
\sum_{i=1}^{n} I_{\operatorname{drp}_{i}}+\sum_{j=1}^{m} I_{\text {power }_{j}}=0
$$

where $I_{\mathrm{drp} i}$ is the current of one droop controlled converter while $I_{\text {power } j}$ is the current of one power controlled converter.

Normally the converters in droop control will operate in their active region (if any) which gives

$$
I_{\mathrm{drp}_{i}}=I_{\mathrm{ord} i}-\frac{1}{k_{i}} \times V_{\mathrm{drp}_{i}}+\left(\frac{1}{k_{i}} \times \operatorname{LRSP}_{i}\right)
$$

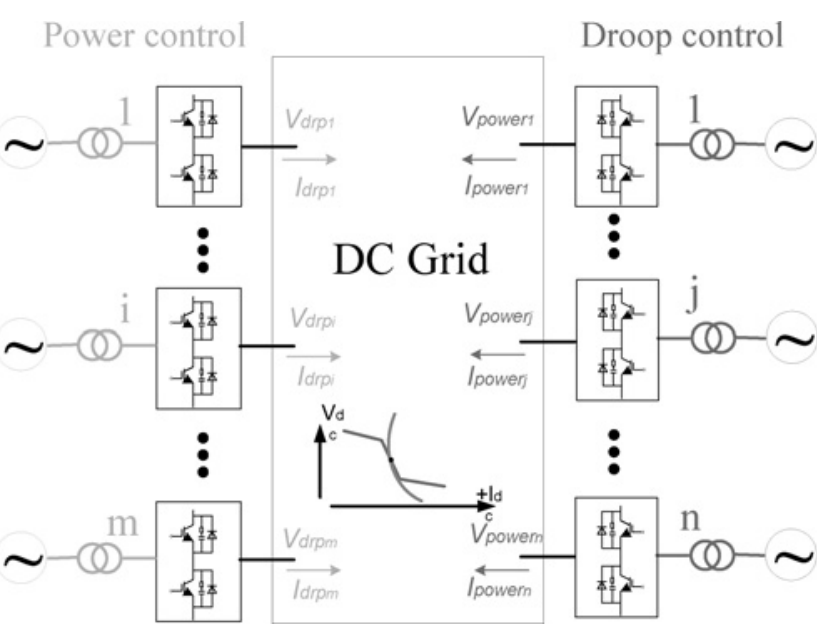

Fig. 7 DC grid integrated with $n$ converters in droop control and $m$ converters in power control 
Currents of converters in power control can be calculated as

$$
I_{\text {power }_{j}}=\frac{P_{\text {power }_{j}}}{V_{\text {power }_{j}}}
$$

Substituting (2) and (3) into (1) gives

$$
\sum_{i=1}^{n}\left(I_{\text {ord }_{i}}\right)-\sum_{i=1}^{n}\left(\frac{1}{k_{i}} \times V_{\mathrm{drp}_{i}}\right)+\sum_{i=1}^{n}\left(\frac{1}{k_{i}} \times \mathrm{LRSP}_{i}\right)+\sum_{j=1}^{m}\left(\frac{P_{\text {power }_{j}}}{V_{\text {power }_{j}}}\right)=0
$$

where $V_{\mathrm{drp} i}$ and $V_{\text {powerj }}$ are the measured voltages of droop controlled converters and power controlled converters.

For simplicity, assuming all droop controlled converters have the same LRSP, and all power converters maintain constant power, for an ideal DC grid

$$
\left(V_{\mathrm{drp}}=V_{\mathrm{drp}_{i}}=V_{\text {power }_{j}}\right),
$$

To find slopes of the equivalent control characteristics of all converters in power control and all converter in droop control the derivative of (4) can be taken with respect to voltage $\left(V_{\mathrm{drp}}\right)$

$$
-\sum_{i=1}^{n}\left(\frac{1}{k_{i}}\right)+\sum_{j=1}^{m}\left(\frac{P_{\text {order } j}}{\mathrm{LRSP}^{2}}\right)=0
$$

From (6), the term $1 / \sum_{i=1}^{n}\left(1 / k_{i}\right)$ can be considered as the droop gain of the merged droop control curve and $1 / \sum_{j=1}^{m}\left(P_{\text {order } j} /\right.$ LRSP $\left.^{2}\right)$ can be considered as the slope of the merged power curve.

Both terms (i.e. $1 / \sum_{i=1}^{n}\left(1 / k_{i}\right)$ and $\left.1 / \sum_{j=1}^{m}\left(P_{\text {order } j} / \mathrm{LRSP}^{2}\right)\right)$ reflect the DC voltage response of changing the current through all the droop controlled converters and the power controlled converters.
Equation (6) should then be satisfied to avoid multiple curve crossing:

$$
\left|\frac{1}{\sum_{i=1}^{n}\left(1 / k_{i}\right)}\right| \leq\left|\frac{1}{\sum_{j=1}^{m}\left(P_{\text {order } j} / \text { LRSP }^{2}\right)}\right|
$$

From (7), it can be concluded that:

- In an ideal DC grid, multiple operation points can only exist when there is at least one export converter in power control and the sum of current flowing through power controlled converters should be negative (i.e. export).

- Higher absolute values of $1 /\left(\sum_{i=1}^{n}\left(1 / k_{i}\right)\right)$ are more likely to cause multiple operation points.

- The increase of LRSP can allow higher droop gain to be selected.

- The decrease of sum of power orders $\sum_{j=1}^{n}\left(P_{\text {ord } j}\right)$ allows higher droop gain to be selected.

\section{Verification}

To verify the effects of multiple cross-overs in the static characteristics, digital simulation using PSCAD and experiments using a physical 'analogue' model [16] were undertaken.

Simulation using digital computing methods is undoubtedly more precise and allows far more complex systems to be studied than would be possible with a physical model. However a digital simulation is only as good as the data that is put in; 'unknowns' are simply omitted. Physical simulation still has its place in the exploration of effects of parameters that might not always be apparent and provides a valuable validation tool for the more precise, detailed and exhaustive digital simulation studies [17].

\subsection{System configuration}

The HVDC test rig (Fig. 8a) uses autotransformers connecting the laboratory $415 \mathrm{~V}$ AC power supply to represent two onshore AC grid connection points (GS1 and GS2) and motor-generator units (back-back permanent magnet synchronous machines) are used to
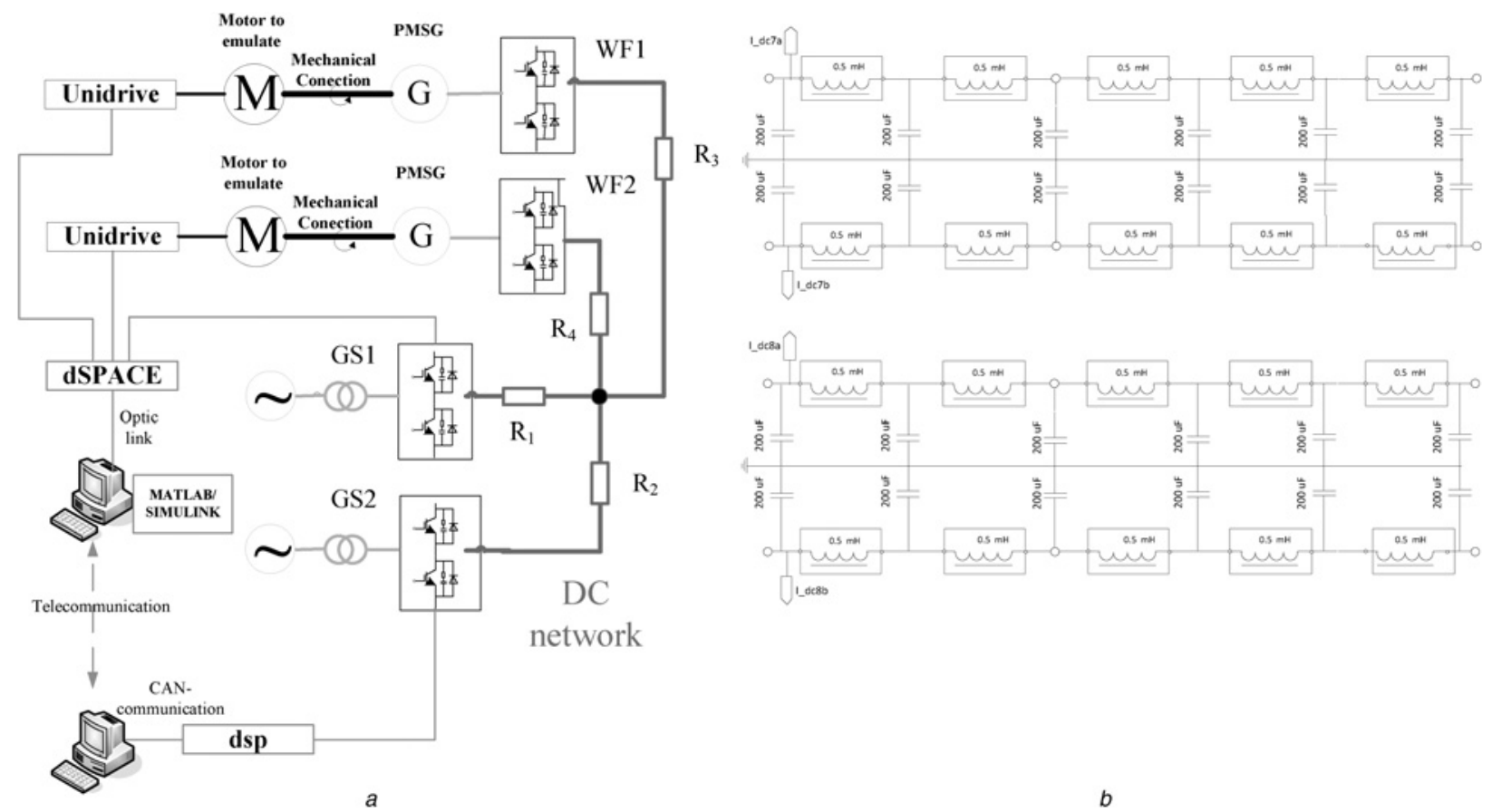

Fig. 8 HVDC test rig

$a$ HVDC test rig set-up

$b$ DC cable model 


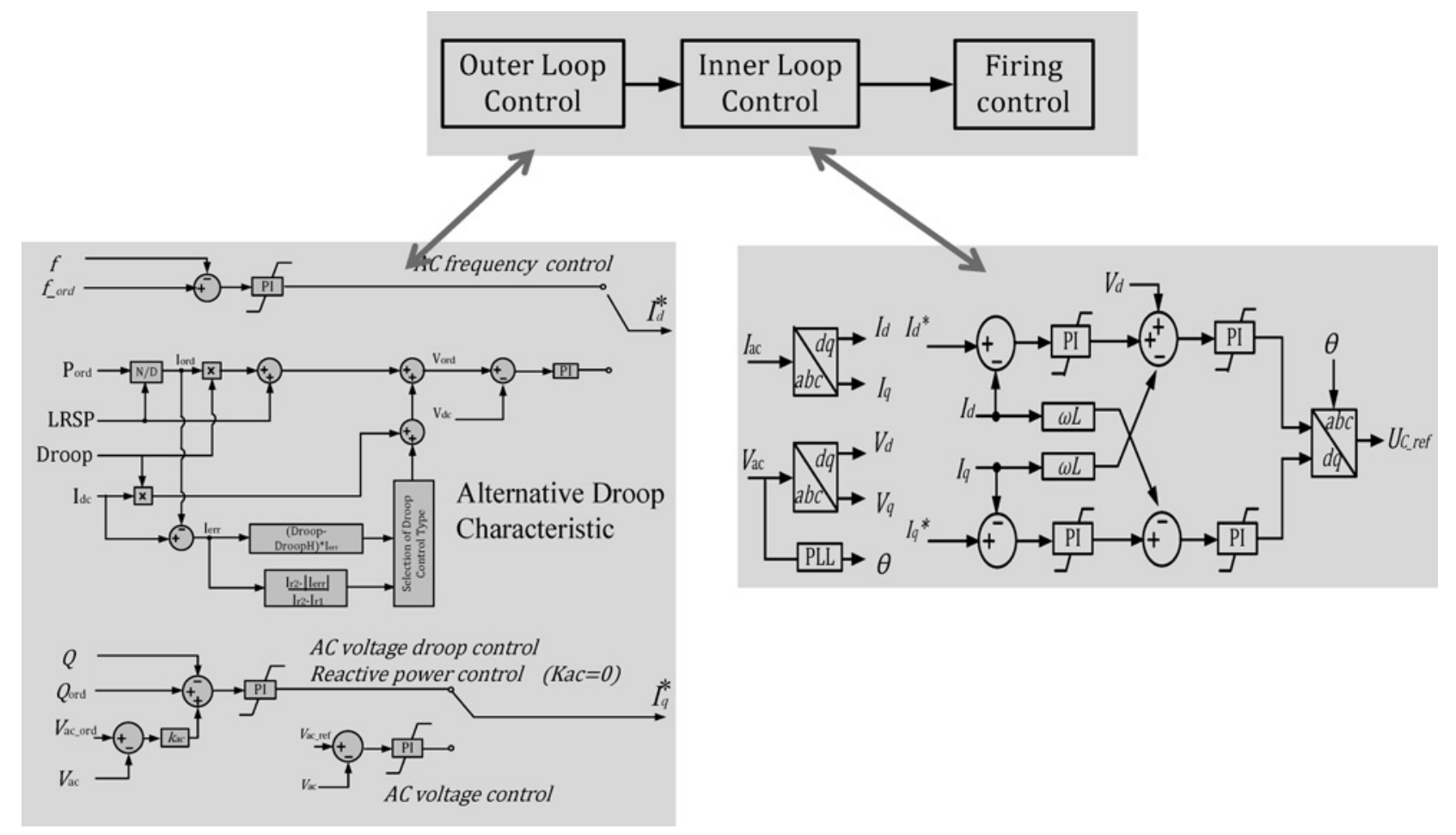

Fig. 9 Hierarchical structure of converter control

represent offshore wind farms. The latter are driven by unidrive inverters to emulate the operation of wind farms. The motor-generator units are then connected to the DC links through the two AC/DC converters (WF1 and WF2).

The specifications and parameters of the test rig are given [18]. The converters are star connected with four DC-circuit cable representations, each composed of $10 \pi$ sections (Fig. $8 b$ ).

\subsection{Control module implementation}

Three of the converters (WF1 WF2 and GS1) are controlled by a dSPACE control board and the fourth converter (GS2) is controlled via a digital signal processor.

\subsection{Converter control module implementation}

The converter control module has a hierarchical structure as shown in Fig. 9.

The outer loop control generates the $d q 0$ frame current references $\left(I_{d}^{*}, I_{q}^{*}\right)$ by using different control modes. The generated $d q 0$ frame current references are sent to the inner loop control. In turn, the decoupled current control acts to output a reference value of the converter AC voltage $\left(U_{C_{C} \text { ref }}\right)$.

The generated control signals are sent to the firing control block to create converter switching signals.

Different control characteristics can be implemented, for example, the autonomous DC voltage droop control could be selected for an onshore converter while AC frequency control (effective power control) could be selected for an offshore converter. In addition the converters can either control the $\mathrm{AC}$ voltage or reactive power.

\section{Simulation results}

\subsection{Digital simulation results}

The following figures are from a digital simulation (PSCAD) of a simple four terminal DC systems (Fig. 8a) with behavioural (equivalent) models for the VSC converters. To show the multiple-crossover characteristics two of the converters control their power to zero whilst the other two converters are in droop (rectifier) or constant power (inverter) control. Basic data of these two converters are:

Rating $1.5 \mathrm{GW}, 400 \mathrm{kV}_{\mathrm{dc}}\left( \pm 200 \mathrm{kV}_{\mathrm{dc}}\right) @ 3.75 \mathrm{kA}_{\mathrm{dc}}$.

Power ramp 0 to $1500 \mathrm{MW}$.

Import converter droop control

Outside ctive region $=-5 \%$

Inside active region $=-125 \%$

$\operatorname{Active}$ region $\left(V_{\mathrm{dc}}\right)= \pm 4 \%$

Export converter constant $P_{\mathrm{dc}}$ control

(note: each DC cable resistance $=0.15 \Omega$ ).

Fig. $10 a$ shows a power ramp with the import converter with a simple droop characteristic. As both converters have the same power order (zero communications delay) it would be expected that the DC voltage would remain at the ordered LRSP of $400 \mathrm{kV}$ however a combination of a lag introduced by the power control loop and the effect of the changing DC current on the system inductances gives a small change in the DC Voltage $\left(2 \mathrm{kV}_{\mathrm{dc}}\right)$. Once the power ramp is completed the DC voltage returns to its LRSP $\left(400 \mathrm{kV}_{\mathrm{dc}}\right)$.

Fig. $10 b$ is the same test with the import converter with the alternative droop characteristic. The $\mathrm{DC}$ voltage does not return to the ordered LRSP $\left(400 \mathrm{kV}_{\mathrm{dc}}\right)$, that is, OP2 at the end of the ramp (note in this example OP $1=425 \mathrm{kV} \mathrm{OP} 2=400 \mathrm{kV}, \mathrm{OP} 3=375$ $\mathrm{kV}$ ). Again the voltage drop during the power ramp at $t=5 \mathrm{~s}$ through to $t=6 \mathrm{~s}$ is the same as in the previous example but now with the addition of the operating point moving down the active region of the droop characteristic to OP3.

An additional test (Fig. 10c) shows that the problem does not exist when the alternative droop is used on an export converter. The power is ramped from $0 \mathrm{MW}$ to $-1500 \mathrm{MW}$ while DC voltage stays at OP2 in steady-state.

\subsection{Analogue simulation results}

A similar test, conducted on the DC grid simulator (physical analogue model) using two level PWM type VSC converters also 


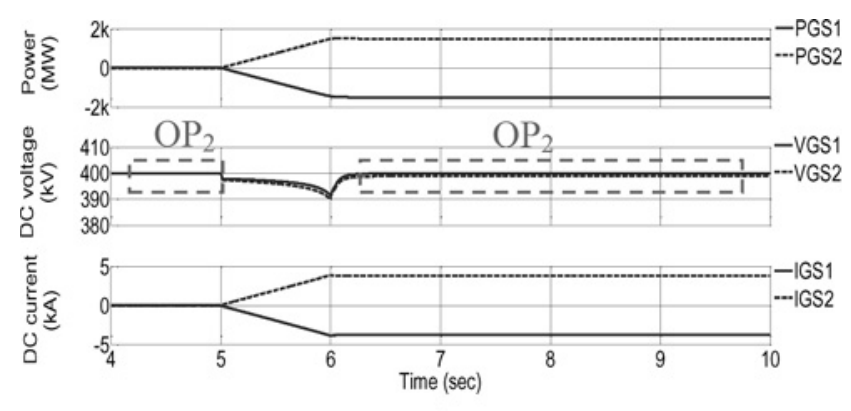

a
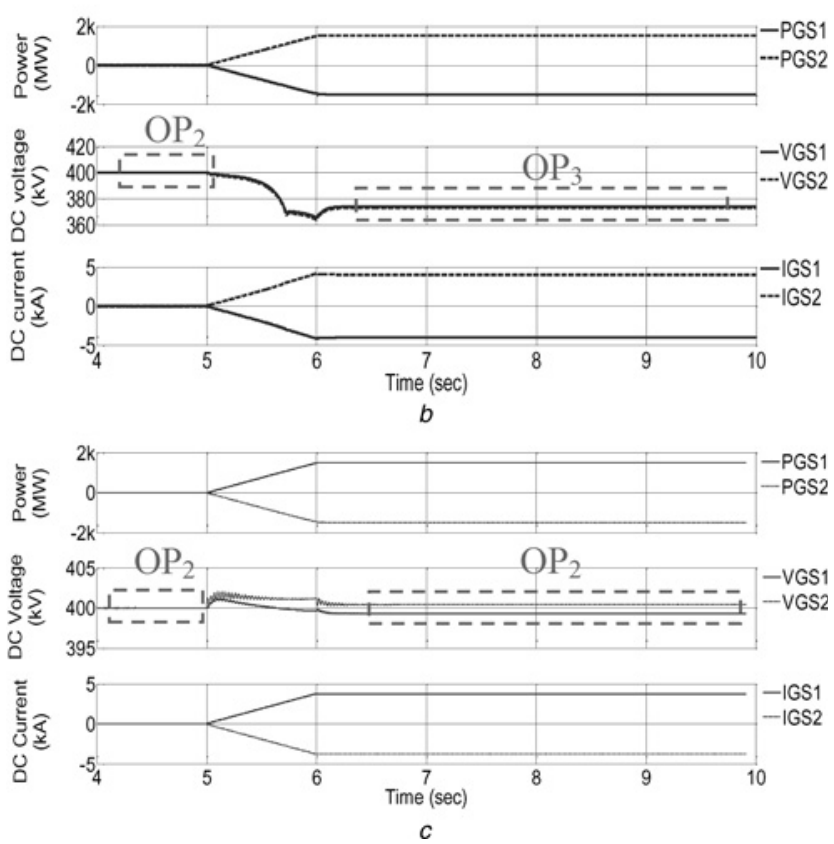

Fig. 10 Power ramp with the import converter with a simple droop characteristic

$a$ Digital simulation of simple droop characteristic (power ramp 0 to $1500 \mathrm{MW}$ ) $b$ Digital simulation of alternative droop characteristic (power ramp 0 to $1500 \mathrm{MW}$ ) $c$ Digital simulation of alternative droop characteristic (power ramp 0 to $-1500 \mathrm{MW}$ )

illustrates the effect of a power ramp ( 0 to $750 \mathrm{~W})$. The basic circuit configuration remains the same.

Basic system data:

Rating $10 \mathrm{~kW}, 800 \mathrm{~V}_{\mathrm{dc}}\left( \pm 400 \mathrm{~V}_{\mathrm{dc}}\right) @ 12.5 \mathrm{~A}_{\mathrm{dc}}$

Operation Rating $750 \mathrm{~W}, 250 \mathrm{~V}_{\mathrm{dc}}\left( \pm 125 \mathrm{~V}_{\mathrm{dc}}\right) @ 3 \mathrm{~A}_{\mathrm{dc}}$

Power ramp 0-750 W

Import converter Droop control

Outside active region $=-8 \%$

Inside active region $=-80 \%$

Active region $\left(V_{\mathrm{dc}}\right)= \pm 4 \%$

Export converter constant $P_{\mathrm{dc}}$ control

GS1 (- $(-)$ in droop control, exporting converter

GS2 (--- ) in Power control, importing converter

Power ramp $0-750 \mathrm{~W}$ in 1 second.

The results of a power ramp with the import converter in droop control and alternative droop control are shown in Figs. 11a and $b$, respectively. Whilst not identical to those of the digital simulation they have similar responses. The principle differences being due to different power control gain and dynamic settings. Fig. $11 \mathrm{c}$ also shows that multiple operating points do not exist when the import converter with alternative droop characteristic changes to an export converter.
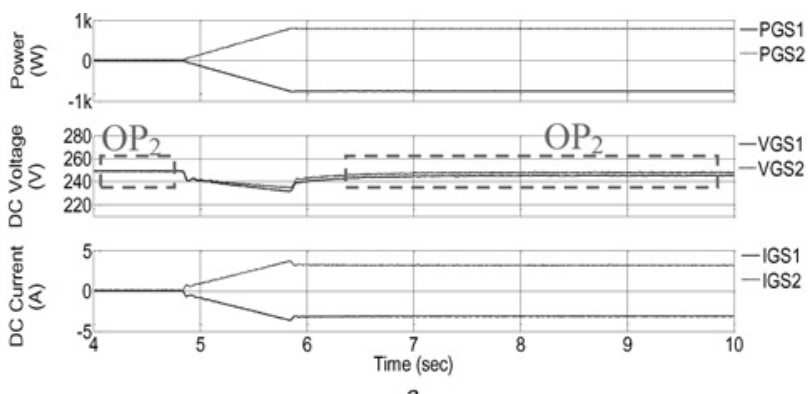

a
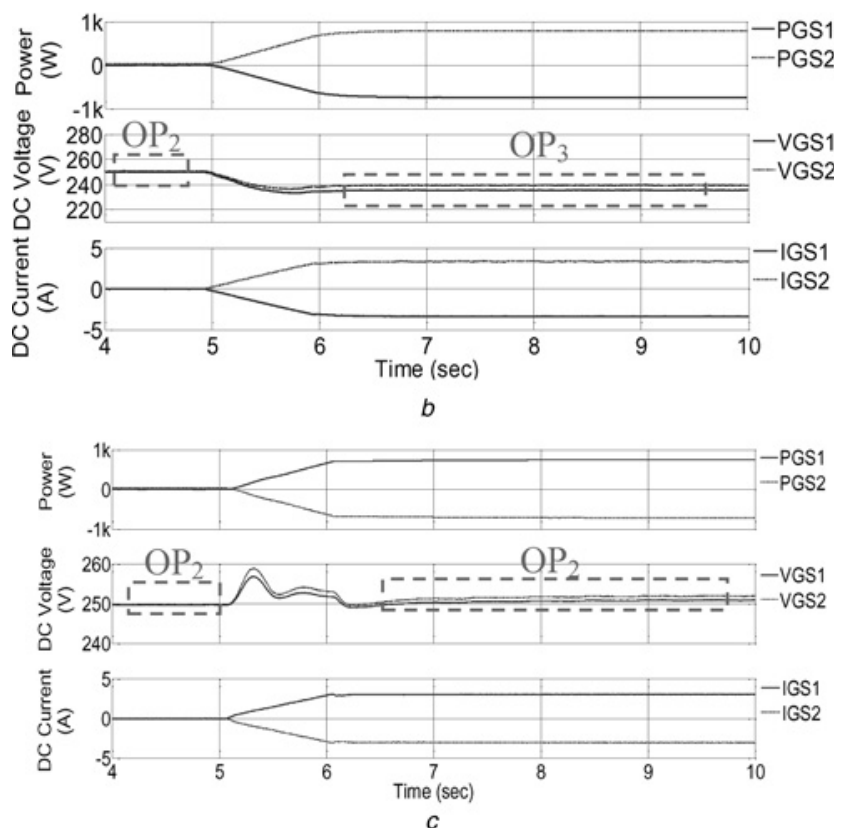

Fig. 11 Results of a power ramp with the import converter in droop control and alternative droop control

$a$ DC grid simulator: simple droop characteristic (power ramp 0 to $750 \mathrm{~W}$ ) $b$ DC grid simulator: alternative droop characteristic (power ramp 0 to $750 \mathrm{~W}$ $c$ Grid simulator: alternative droop characteristic (power ramp 0 to $-750 \mathrm{~W}$ )

\section{Conclusion}

The use of droop control characteristics for converters has previously been shown to be a stable method of controlling power flow in HVDC grids. The effect of such an approach is generally regarded as beneficial in sharing the duty of maintaining power balance within the grid amongst all of the converters. For converters attached to sensitive AC systems it has been suggested that alternative droop characteristics are employed to allow them greater control over their own power exchange with their AC system. Previous work suggested no adverse interactions between this control methodology and other types of control such as constant power control. However the studies undertaken by Cardiff University in collaboration with Alstom Grid UK now show that for the single case of constant power controlled export stations (inverters) and alternative type droop control import stations (rectifiers) may give rise to multiple characteristic intersections and ambiguous operating conditions for some modified droop characteristics. This can occur when the slope of the droop characteristic is similar to the tangential slope of the power characteristic at, or near to, the operating point. Analysis has shown that it is possible to mitigate this effect by ensuring that the aggregate droop of all of the droop controlled converters is smaller than that of the tangential slope of the aggregate of the power controlled converters. Alternatively by ensuring that in any HVDC grid where an exporting station is in constant power control all droop converters are operated with a 
simple droop characteristic and thus eliminating the possibility of multiple operating points. The disadvantage of this approach will be that small errors in the control system and/or measurements transducers or changes in other converter operation will lead to all such converters operating away from their intended DC power. However, this unintended consequence will only persist until the Grid Control re-dispatches new operating orders and restores power balance amongst the converters.

\section{References}

1 MacLeod, N.M., Sukar, I.R., Emin, Z.: 'Enhancing system performance by means of HVDC transmission'. CIGRE Int. Conf., GCC Power 2013, Abu Dhabi, United Arab Emirates, November 2013

2 Adeuyi, O.D., Jenkins, N., Wu, J.: 'Topologies of the north sea supergrid'. 2013 48th Int. Universities' Power Engineering Conf. (UPEC)

3 Adam, P.: 'Technological and innovation challenges for implementing a Mediterranean grid' April 11th 2013 - European Parliament Brussels Belgium

4 CLC/TR 50609:2014: 'Technical guidelines for radial HVDC networks'. (Frankfurt, European, 2012)

5 Zhu, J., Guerrero, J.M., Hung, W., et al.: 'Generic inertia emulation controller for multi-terminal voltage-source-converter high voltage direct current systems', IET Renew. Power Gener., 2014, 8, (7), pp. 740-748

6 Xu, L., Yao, L.: 'DC voltage control and power dispatch of a multi-terminal HVDC system for integrating large offshore wind farms', IET Renew. Power Gener., 2011, 5, (3), pp. 223-233

7 Dai, J., Phulpin, Y., Sarlette, A., et al.: 'Coordinated primary frequency control among non-synchronous systems connected by a multi-terminal high-voltage direct current grid', IET Gener. Transm. Distrib., 2012, 6, (2), pp. 99-108
8 Dierckxsensa, C., Srivastavab, K., Rezab, M., et al.: 'A distributed DC voltage control method for VSC MTDC systems', Electr. Power Syst. Res., 2012, 82, (1), pp. $54-58$

9 Liang, J., Jing, T., Gomis-Bellmunt, O., et al.: 'Operation and control of multiterminal HVDC transmission for offshore wind farms', IEEE Trans. Power Deliv., 2011, 26, (4), pp. 2596-2604

10 Jovcic, D., Strachan, N.: 'Offshore wind farm with centralised power conversion and DC interconnection', IET Gener. Transm. Distrib., 2009, 3, (6), pp. 586-595

11 Egea-Alvarez, A., Beerten, J., Van Hertem, D., et al.: 'Primary and secondary power control of multiterminal HVDC grids'. IET Int. Conf. on AC and DC Power, Birmingham, 2012

12 Vrana, T.K., Zeni, L., Fosso, O.B.: 'Dynamic active power control with improved undead-band droop for HVDC grids'. IET Int. Conf. on AC and DC Power, Birmingham, 2012

13 Rouzbehi, K., Miranian, A., Luna, A., et al.: 'DC voltage control and power sharing in multiterminal DC grids based on optimal DC power flow and voltage-droop strategy', Emerging Sel. Topics Power Electron., 2014, 2, (4), pp. $1171-1180$

14 Barker, C.D., Whitehouse, R.: 'Autonomous converter control in a multi-terminal HVDC system'. IET Int. Conf. on AC and DC Power, London, 2010

15 Barker, C.D., Whitehouse, R.S.: 'Further developments in autonomous converter control in a multi-terminal HVDC system'. IET Int. Conf. on AC and DC Power, Birmingham, 2012

16 Wang, S., Barker, C.D., Whitehouse, R.S., et al.: 'Experimental validation of autonomous converter control in a HVDC grid'. European Conf. on Power Electronics and Applications, Lappeenranta, 2014

17 Whitehouse, R.S., Oates, C.D.M., Maneiro, J., et al.: 'A new simulator laboratory for research and development of VSC HVDC topologies and control algorithms' IET Int. Conf. on AC and DC Power, London, 2010

18 Barker, C., Whitehouse, R., Wang, S., et al.: 'Risk of multiple cross-over of control characteristics in multi-terminal HVDC'. IET Int. Conf. on AC and DC Power, Birmingham, 2015 